\title{
Genetic analysis of agronomic traits associated with plant architecture by QTL mapping in maize
}

\author{
Z.P. Zheng ${ }^{1}$ and X.H. Liu ${ }^{2}$ \\ ${ }^{1}$ Nanchong Academy of Agricultural Sciences, Nanchong, P.R. China \\ ${ }^{2}$ Key Laboratory of Southwest China Wildlife Resources Conservation, \\ Ministry of Education, College of Life Sciences, \\ China West Normal University, Nanchong, P.R. China \\ Corresponding author: X.H. Liu \\ E-mail: liuxiaohong0817@yahoo.com.cn
}

Genet. Mol. Res. 12 (2): 1243-1253 (2013)

Received July 30, 2012

Accepted January 30, 2013

Published April 17, 2013

DOI http://dx.doi.org/10.4238/2013.April.17.3

\begin{abstract}
Maize (Zea mays L.) is one of the most important cereal crops worldwide, and increasing the grain yield and biomass has been among the most important goals of maize production. The plant architecture can determine the grain yield and biomass to some extent; however, the genetic basis of the link between the plant architecture and grain yield/biomass is unclear. In this study, an immortal $\mathrm{F}_{9}$ recombinant inbred line population, derived from the cross Mo17 $\mathrm{x}$ Huangzao4, was used to detect quantitative trait loci (QTLs) for 3 traits associated with plant architecture under two nitrogen regimes: plant height, ear height, and leaf number. As a result, 8 and 10 QTLs were identified under the high nitrogen regime and low nitrogen regime, respectively. These QTLs mapped to chromosomes 1 (six QTLs), 2 (one QTL), 3 (one QTL), 7 (two QTLs), and 9 (eight QTLs), and had different genetic distances to their closest markers, ranging from 0 to $22.0 \mathrm{cM}$, explaining 4.7 to $20.5 \%$ of the phenotypic variance. Because of an additive effect, 9 and 9 could make the phenotypic values of traits increase and decrease to some extent, respectively. These results
\end{abstract}


are beneficial for understanding the genetic basis of agronomic traits associated with plant architecture and for performing marker-assisted selection in maize breeding programs.

Key words: Maize; QTL; Plant architecture; Nitrogen regime

\section{INTRODUCTION}

Maize (Zea mays L.) is one of the most important cereal crops worldwide, and increasing the grain yield and biomass per acre has been among the most important goals of maize production (Ku et al., 2010). Several decades of breeding efforts, striving for consistent performance under elite-hybrid popularization and high-density plantings, have enhanced the genetic gain of yield. The remarkable importance of plant architecture in maize is well underlined by retrospective analyses of hybrids (Tollenaar and Wu, 1999; Lu et al., 2010). Among the agronomic traits that have changed markedly as a result of selection, plant architecture, e.g., plant height $(\mathrm{PH})$ and ear height $(\mathrm{EH})$, has played a predominant role in adaptation to the historical increase in yield (Zhang et al., 2010). With the arable land gradually decreasing, it is likely that increased planting density will continue to be a target for selection in the future (Kebrom and Brutnell, 2007). Hence, breeding of maize with optimized plant architecture is regarded as one of the most important goals in maize breeding projects.

Many traits such as $\mathrm{PH}, \mathrm{EH}$, leaf number (LN), leaf angle (LA), and leaf orientation (LO) can be used to evaluate the efficiency of plant architecture. More significantly, these traits associated with plant architecture can be largely used to determine grain yield and biomass (Ribaut et al., 2007; Liao et al., 2011). To obtain plant varieties possessing the desired architecture, conventional breeding methods are useful; however, these methods are timeconsuming due to the selection of superior individuals among segregating progenies resulting from hybridization (Ibitoye and Akin-Idowu, 2010). Moreover, the available maize materials are limited. An alternative solution is to utilize marker-assisted selection (MAS). MAS is a combination of traditional genetics and molecular biology and allows for the selection of genes that control traits of interest. Combined with traditional selection techniques, MAS has emerged as a valuable tool for selecting organisms with interesting traits during crop breeding (Stendal et al., 2006; Chen et al., 2010; Kumar et al., 2010; Jantaboon et al., 2011).

To perform MAS, an understanding of the genetic basis of traits is necessary, and quantitative trait locus (QTL) mapping for traits can help us achieve this purpose. Currently, QTL mapping has been applied for crop improvement (Kumar and Kumar, 2009), and a large number of molecular markers linked with traits have been obtained; moreover, some QTLs controlling agronomic traits have been successfully cloned (Zhou et al., 2011). In maize, numerous QTLs have been identified that control agronomic traits, and these QTLs have been mapped to 10 chromosomes in maize (Tsonev et al., 2009; Qiu et al., 2011). For the traits related to plant architecture, $\mathrm{PH}$ and $\mathrm{EH}$ have been frequently studied (Kraja and Dudley, 2000; Sibov et al., 2003; Lima et al., 2006; Malosetti et al., 2008; Bai et al., 2010), and a large number of QTLs were found to be located in different chromosomal regions. There are also many reports on QTL identification of the LN trait (Jiang et al., 1999; Lima et al., 2006; Tang et al., 2007; Wang et al., 2008), and several studies have been performed on the LA and LO traits (Mickelson et al., 2002; Lu et al., 2007; Ku et al., 2010). Therefore, QTL mapping of traits associated with plant architecture is very significant in maize. 
A segregating population must be used for QTL mapping. Previous studies of QTL mapping of maize agronomic traits focused on $\mathrm{F}_{2}$ (Ribaut et al., 2007; Ku et al., 2010; Zhang et al., 2010). This kind of population has a deficiency, namely, temporality, similar to a backcross population (Bai et al., 2010). Thus, $\mathrm{F}_{2}$ cannot be utilized again because there are no continual plants for DNA extraction and phenotypic analysis. In comparison, the recombinant inbred line (RIL) population is immortal and can be used in different regions and times because it consists of homogenous individuals. The RIL population has been widely used for QTL mapping in crops (Balint-Kurti et al., 2008; Du et al., 2009; Blair et al., 2010; Zhou et al., 2011), but it has rarely been used for QTL mapping for traits associated with plant architecture in maize (Tang et al., 2007; Liu et al., 2010). Additionally, the same type of segregating population derived from different parental lines likely provide different QTL identification results, including different location, number, and genetic effects. Thus, an RIL population that is derived from two parental lines and that is different from previous studies is necessary to be selected to map QTLs for PH, EH, and LN, associated with plant architecture in maize.

Moreover, QTL mapping can be affected by ecological conditions because the same genes under different environments might be expressed at different levels. For example, using the $\mathrm{F}_{2}$ population from the cross X178 x B73, Xiao et al. (2005) identified 2 QTLs on chromosomes 1 and 9 in a well-watered environment. In contrast, in a water-stressed environment, 3 QTLs were mapped on chromosomes 1, 2, and 9. Until now, most ecological environments used for QTL mapping of maize traits have been focused on different water contents in the soil, involving different water regimes in the same field or different experimental regions with different rainfall rates (Messmer et al., 2009; Zhang et al., 2010; Hao et al., 2011). However, low nitrogen $(\mathrm{N})$ conditions, for example, during agricultural drought, represent a major source of loss in maize yield. Currently, most maize in developing countries is produced under $\mathrm{N}$-deficient conditions because of the low $\mathrm{N}$ availability in drought-prone environments, high price ratios between fertilizers and grains, limited availability of fertilizers, and low purchasing power of farmers (Ribaut et al., 2007). Thus, there is a growing interest in developing cultivars performing better under low $\mathrm{N}$ conditions. A better understanding of the genetic basis of the maize plant architecture under N-stressed conditions is necessary and can help facilitate the selection efficiency of crops for these environments.

Therefore, in this present study, an $\mathrm{F}_{9}$ RIL population, derived from the cross between maize inbred lines Mo17 (Lancaster heterotic group in the USA) and Huangzao4 (Tangsipingtou heterotic group in China), were used to identify QTLs for 3 traits affecting plant architecture under $2 \mathrm{~N}$ regimes: $\mathrm{PH}, \mathrm{EH}$, and $\mathrm{LN}$. The objectives were to i) better understand the genetic basis of plant architecture and ii) identify molecular markers for MAS in maize breeding projects.

\section{MATERIAL AND METHODS}

\section{Maize materials}

The experimental materials involved in this study included maize inbreeds Mo17 (female) and Huangzao4 (male) as parents, and an $F_{1}$ hybrid and an $F_{9}$ segregation population consisting of 239 RILs. Mo17 and Huangzao4 are representative lines of the Lancaster and Tangsipingtou heterotic groups, respectively. The $\mathrm{F}_{1}$ hybrid and the RIL population descended from the cross between these two parental lines. 


\section{Field experiments}

At the Nanchong Academy of Agricultural Sciences, Nanchong city, China, these 242 lines were sown in a randomized complete block design with 6 replicates, 15 plants per plot in each replicate. Of the 6 replicates in each line, 3 were placed under a high $\mathrm{N}$ regime (HNR) by adding urea $(300 \mathrm{~kg} / \mathrm{ha})$, and the other 3 were placed under a low $\mathrm{N}$ regime (LNR) with no added $\mathrm{N}$-containing fertilizer. The average contents of total $\mathrm{N}$ and alkaline hydrolysis $\mathrm{N}$ at a depth of $30 \mathrm{~cm}$ in the original soil were 0.092 and $0.000056 \%$, respectively.

\section{Phenotype investigation and statistical analysis}

During the flowering period, the middle 8 plants of each replicate of the 242 lines were individually recorded, and the means of the 3 traits, $\mathrm{PH}$ (centimeters; from plant base to tasseling tip), EH (centimeters; from plant base to ear base), and LN (total number of leaves), were calculated.

The SPSS 11.5 software (www.spss.com) was used to analyze the phenotypic data of the traits, as described by Liu et al. (2009). First, descriptive statistics was performed to calculate the mean and standard deviation (SD) for the parental lines and the $\mathrm{F}_{1}$ hybrid, as well as the range, mean, SD, skewness, kurtosis, and frequency distribution for the RIL population. Second, ANOVA was performed to determine the significance of differences between individuals within the RIL population. According to Li et al. (2012), the broadsense heritability of a population based on the 3 traits in the $2 \mathrm{~N}$ environments is calculated using the formula $\mathrm{H}^{2}=\sigma_{\mathrm{g}}^{2} /\left(\sigma_{\mathrm{g}}^{2}+\sigma_{\mathrm{e}}^{2} / \mathrm{n}\right)$, where $\sigma_{\mathrm{g}}^{2}$ is the genotypic variance, $\sigma_{e}^{2}$ is the environmental variance, and $n$ is the number of replicates. The variance between HNR and LNR were compared by ANOVA for the RIL population. Each of the 3 phenotypic traits was modeled independently using a mixed procedure, where the genotype, location, and interaction between the location and the genotype were defined as a fixed effect, whereas the replication within a location (block effect) was defined as a random effect. Finally, Pearson's correlation coefficients between the 3 traits in the $2 \mathrm{~N}$ regimes were calculated and analyzed.

\section{QTL identification}

To conduct the QTL mapping for PH, EH, and LN, the means of each line of the RIL population under the same $\mathrm{N}$ condition were computed for the 24 plants in 3 replicates. According to a previous linkage map that included 100 microsatellite markers and covered $1421.5 \mathrm{cM}$ of the genome (Liu et al., 2009), QTL detection affecting the 3 traits was performed via composite interval mapping (CIM) (Wang et al., 2010), using the following control parameters: $10-\mathrm{cM}$ window size, CIM standard model, 5 control markers, and forward regression method. The $\log _{10}$ of the odds ratio (LOD) threshold value for the QTL significance was determined by the 1000-time permutation test $(\alpha=0.05)$ (Doerge and Churchill, 1996). The position, percentage of phenotypic variation, and genetic effects of the identified QTLs were estimated on the basis of the peak of the LOD curve region over the threshold values, and the identified QTLs were then mapped using the Mapchart 2.1 software (Voorrips, 2012). 


\section{RESULTS}

\section{Statistical analysis}

\section{Descriptive statistics of traits in the parental lines and the $F_{1}$ hybrid}

The statistical results showed differences between Mo17, Huangzao4, and the $\mathrm{F}_{1}$ hybrid (Table 1). The mean of the $\mathrm{F}_{1}$ hybrid was significantly greater than that of the parental lines for all of the investigated traits under either $\mathrm{N}$ regime, a phenomenon best explained by heterosis. Of the two parents, Mo17 had a higher value for the PH trait, whereas Huangzao4 had a higher value for the LN trait. EH is a special trait, and Huangzao4 had a higher value under HNR. In contrast, under LNR, the value for the EH trait in Huangzao4 was lower than that in Mo17.

\begin{tabular}{|c|c|c|c|c|}
\hline Traits & $\mathrm{N}$ regimes & $\begin{array}{c}\text { Mo17 } \\
(\text { mean } \pm \text { SD) }\end{array}$ & $\begin{array}{c}\mathrm{HZ4} \\
(\mathrm{mean} \pm \mathrm{SD})\end{array}$ & $\begin{array}{c}\mathrm{F}_{1} \\
(\mathrm{mean} \pm \mathrm{SD})\end{array}$ \\
\hline \multirow[t]{2}{*}{$\mathrm{PH}(\mathrm{cm})$} & HNR & $211.40 \pm 10.40$ & $181.90 \pm 5.43$ & $245.03 \pm 6.01$ \\
\hline & LNR & $200.20 \pm 6.40$ & $173.23 \pm 21.45$ & $245.57 \pm 4.59$ \\
\hline \multirow[t]{2}{*}{$\mathrm{EH}(\mathrm{cm})$} & HNR & $77.70 \pm 5.77$ & $82.90 \pm 3.64$ & $101.87 \pm 4.80$ \\
\hline & LNR & $79.33 \pm 15.33$ & $78.77 \pm 10.90$ & $90.10 \pm 12.01$ \\
\hline \multirow[t]{2}{*}{ LN } & HNR & $17.00 \pm 0.10$ & $18.50 \pm 0.10$ & $19.07 \pm 0.12$ \\
\hline & LNR & $16.77 \pm 0.45$ & $18.53 \pm 0.23$ & $19.00 \pm 0.00$ \\
\hline
\end{tabular}

\section{Descriptive statistics of traits in the RIL population}

The results of the descriptive statistics for the 3 traits across the $2 \mathrm{~N}$ regimes in the RIL population are listed in Table 2. In general, there were no significant differences between the $2 \mathrm{~N}$ regimes for the same trait using the 3 parameters, including the range, mean, and SD. However, the skewness and kurtosis showed differences, and computation of the statistical significance of the differences between the $2 \mathrm{~N}$ regimes was deemed unnecessary. The frequency distribution graphs of the data derived from different RILs within the population are indicated in Figure 1. From these results, we concluded that the statistics of the 6-group data agreed well with a normal distribution, suggesting that the $\mathrm{PH}, \mathrm{EH}$, and $\mathrm{LN}$ of maize are quantitative traits that are controlled by multiple genes.

Table 2. Descriptive statistics of the recombinant inbred line population across 2 nitrogen $(\mathrm{N})$ regimes in 3 traits.

\begin{tabular}{llcrrr}
\hline Traits & N regimes & Range & Mean \pm SD & Skewness & Kurtosis \\
\hline PH $(\mathrm{cm})$ & HNR & $124.10-265.00$ & $198.54 \pm 22.81$ & -0.037 & 0.190 \\
& LNR & $135.40-266.90$ & $199.33 \pm 22.77$ & 0.047 & 0.255 \\
EH $(\mathrm{cm})$ & HNR & $39.30-116.10$ & $78.13 \pm 13.18$ & 0.097 \\
& LNR & $47.10-117.00$ & $77.11 \pm 13.00$ & 0.165 & -0.132 \\
LN & HNR & $15.40-22.00$ & $18.54 \pm 1.20$ & 0.361 & 0.158 \\
& LNR & $14.90-21.80$ & $18.32 \pm 1.20$ & 0.371 \\
\hline
\end{tabular}

$\mathrm{SD}=$ standard deviation; $\mathrm{PH}=$ plant height; $\mathrm{EH}=$ ear height; $\mathrm{LN}=$ leaf number; $\mathrm{HNR}=$ high $\mathrm{N}$ regime; $\mathrm{LNR}=$ low $\mathrm{N}$ regime. 

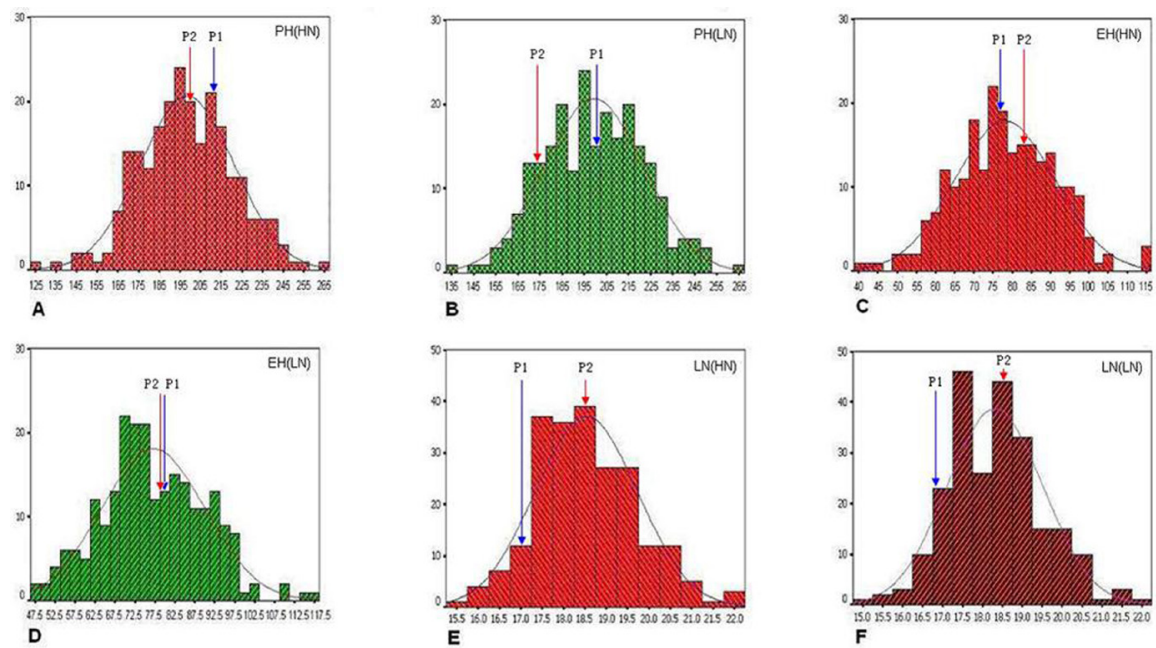

Figure 1. Frequency distribution of 3 traits associated with plant architecture in the population including 239 recombinant inbred lines. Horizontal axis for trait values and longitudinal axis for number of individuals. A. Plant height $(\mathrm{PH})$ under high $\mathrm{N}(\mathrm{HN})$ regime; B. PH under low N (LN) regime; C. ear height (EH) under HN regime; D. $\mathrm{EH}$ under $\mathrm{LN}$ regime; E. leaf number (LN) under $\mathrm{HN}$ regime; $\mathbf{F}$. LN under low $\mathrm{N}$ regime.

\section{ANOVA of traits in the RIL population}

The results of ANOVA for the 3 traits in the RIL population under the $2 \mathrm{~N}$ regimes are shown in Table 3. According to the $F$ values, the 239 RILs of the population presented significant differences at $\mathrm{P}<0.01$ in the 3 traits under both $\mathrm{N}$ regimes. Thus, our maize population could be used for QTL mapping for the 3 agronomic traits across different $\mathrm{N}$ environments.

Table 3. ANOVA of the recombinant inbred line population across 2 nitrogen $(\mathrm{N})$ regimes in 3 traits.

\begin{tabular}{|c|c|c|c|c|c|c|c|}
\hline Traits & $\mathrm{N}$ regimes & Source of variation & Sum of squares & d.f. & Mean square & $F$ & Significance \\
\hline \multirow[t]{4}{*}{$\mathrm{PH}(\mathrm{cm})$} & \multirow[t]{2}{*}{ HNR } & Between groups & 367490.10 & 236 & 1557.16 & \multirow[t]{2}{*}{$16.56 * *$} & \multirow[t]{2}{*}{$<0.01$} \\
\hline & & Within groups & 44476.85 & 473 & 94.03 & & \\
\hline & \multirow[t]{2}{*}{ LNR } & Between groups & 365621.49 & 236 & 1549.24 & \multirow[t]{2}{*}{$13.35 * *$} & \multirow[t]{2}{*}{$<0.01$} \\
\hline & & Within groups & 54793.58 & 472 & 116.09 & & \\
\hline \multirow{4}{*}{$\mathrm{EH}(\mathrm{cm})$} & \multirow[t]{2}{*}{ HNR } & Between groups & 122413.64 & 236 & 518.70 & \multirow[t]{2}{*}{$12.81 * *$} & \multirow[t]{2}{*}{$<0.01$} \\
\hline & & Within groups & 19146.47 & 473 & 40.48 & & \\
\hline & \multirow[t]{2}{*}{ LNR } & Between groups & 119330.16 & 236 & 505.64 & \multirow[t]{2}{*}{$11.75^{* *}$} & \multirow[t]{2}{*}{$<0.01$} \\
\hline & & Within groups & 20313.07 & 472 & 43.04 & & \\
\hline \multirow[t]{4}{*}{ LN } & \multirow[t]{2}{*}{ HNR } & Between groups & 993.29 & 236 & 4.21 & \multirow[t]{2}{*}{$20.20 * *$} & \multirow[t]{2}{*}{$<0.01$} \\
\hline & & Within groups & 95.63 & 459 & 0.21 & & \\
\hline & \multirow[t]{2}{*}{ LNR } & Between groups & 1008.34 & 236 & 4.27 & \multirow[t]{2}{*}{$23.18^{* *}$} & \multirow[t]{2}{*}{$<0.01$} \\
\hline & & Within groups & 86.28 & 468 & 0.18 & & \\
\hline
\end{tabular}

d.f. $=$ degrees of freedom, excluding three missing values. ${ }^{*} *$ Significant probability at 0.01 level. $\mathrm{PH}=$ plant height; $\mathrm{EH}=$ ear height; $\mathrm{LN}=$ leaf number; $\mathrm{HNR}=$ high $\mathrm{N}$ regime; $\mathrm{LNR}=$ low $\mathrm{N}$ regime.

\section{Comparisons between HNR and LNR for the 3 traits of the RIL population}

The heritability was high for all experimental traits, ranging from 97.24 to $98.61 \%$ (Table 4). LN had the highest heritability (98.36\% under HNR and 98.61\% under LNR). EH 
had the lowest heritability (97.24\% under LNR). Statistical analysis using a mixed model for the differences between the HNR and LNR demonstrated that the differences due to the genotypes were significant at $\mathrm{P}<0.01$ for the 3 traits. The differences due to the $\mathrm{N}$ regime were also significant at $\mathrm{P}<0.01$ for $\mathrm{LN}$ and $\mathrm{EH}$; however, no interaction from the genotype $\mathrm{x} N$ regime was different in the $2 \mathrm{~N}$ regimes.

\begin{tabular}{|c|c|c|c|c|c|c|c|c|}
\hline \multirow[t]{2}{*}{ Traits } & \multirow[t]{2}{*}{$\mathrm{N}$ regimes } & \multirow[t]{2}{*}{ Heritability (\%) } & \multicolumn{2}{|c|}{ Genotype } & \multicolumn{2}{|c|}{$\mathrm{N}$ regime } & \multicolumn{2}{|c|}{ Genotype $x \mathrm{~N}$ regime } \\
\hline & & & $F$ & $\operatorname{Pr}>F$ & $F$ & $\operatorname{Pr}>F$ & $F$ & $\operatorname{Pr}>F$ \\
\hline PH (cm) & $\begin{array}{l}\text { HNR } \\
\text { LNR }\end{array}$ & $\begin{array}{l}98.03 \\
97.56\end{array}$ & 29.83 & $<0.01 * *$ & 2.18 & $>0.05$ & 0.83 & $>0.05$ \\
\hline $\mathrm{EH}(\mathrm{cm})$ & $\begin{array}{l}\text { HNR } \\
\text { LNR }\end{array}$ & $\begin{array}{l}97.46 \\
97.24\end{array}$ & 23.88 & $<0.01 * *$ & 8.96 & $<0.01 * *$ & 0.98 & $>0.05$ \\
\hline LN & $\begin{array}{l}\text { HNR } \\
\text { LNR }\end{array}$ & $\begin{array}{l}98.36 \\
98.61\end{array}$ & 43.17 & $<0.01 * *$ & 97.05 & $<0.01 * *$ & 1.18 & $>0.05$ \\
\hline
\end{tabular}

**Significant probability at 0.01 level. $\mathrm{PH}=$ plant height; $\mathrm{EH}=$ ear height; $\mathrm{LN}=$ leaf number; $\mathrm{HNR}=$ high $\mathrm{N}$ regime; $\mathrm{LNR}=$ low $\mathrm{N}$ regime.

\section{Correlation analysis between different traits in the RIL population}

The 3 traits across the $2 \mathrm{~N}$ regimes were further correlated on the basis of the statistical average of the 239 RILs (Table 5). All of the 15 correlation coefficient values derived from the 3 traits crossed by the $2 \mathrm{~N}$ regimes displayed positive correlations at the $\mathrm{P}<0.01$ level.

Table 5. Correlation analysis among the 3 traits for the recombinant inbred line population across 2 nitrogen $(\mathrm{N})$ regimes.

\begin{tabular}{lccccc}
\hline & PH $(\ln )$ & EH (hn) & EH (ln) & LN (hn) & LN (ln) \\
\hline PH (hn) & $0.95^{* *}$ & $0.78^{* *}$ & $0.72^{* *}$ & $0.32^{* *}$ & $0.30^{* *}$ \\
PH (ln) & & $0.73^{* *}$ & $0.75^{* *}$ & $0.28^{* *}$ & $0.29^{* *}$ \\
EH (hn) & & $0.92^{* *}$ & $0.53^{* *}$ & $0.51^{* *}$ \\
EH (ln) & & & $0.49^{* *}$ & $0.53^{* *}$ \\
LN (hn) & & & & $0.95^{* *}$ \\
\hline
\end{tabular}

**Correlation is significant at 0.01 level (Pearson's correlation, two-tailed). PH $(\mathrm{hn})=$ plant height under high $\mathrm{N}$ regime; $\mathrm{PH}(\mathrm{ln})=$ plant height under low $\mathrm{N}$ regimes; $\mathrm{EH}(\mathrm{hn})=$ ear height under high $\mathrm{N}$ regime; $\mathrm{EH}(\mathrm{ln})=$ ear height under low $\mathrm{N}$ regime; $\mathrm{LN}(\mathrm{hn})=$ leaf number under high $\mathrm{N}$ regime; $\mathrm{LN}(\mathrm{ln})=$ leaf number under low $\mathrm{N}$ regime.

\section{QTL identification}

The results of the QTL detection for the PH, EH, and LN traits are shown in Table 6. Eighteen QTLs were detected under the $2 \mathrm{~N}$ regimes: 8 under HNR and 10 under LNR. These QTLs were mapped to chromosomes 1 (six QTLs), 2 (one QTL), 3 (one QTL), 7 (two QTLs), and 9 (eight QTLs). The mapping intervals to the closest markers ranged from 0 to $22.0 \mathrm{cM}$ (Figure 2). From the $\mathrm{R}^{2}$ values in Table 6, the 18 QTLs accounted for 4.7 to $20.5 \%$ of the phenotypic variance. Under HNR, these QTLs for PH, EH, and LN could explain 17.3, 31.8 , and $55.8 \%$ of the phenotypic variance, respectively. In contrast, under LNR, the QTLs accounted for $15.6,51.0$, and $57.6 \%$ of the phenotypic variance, respectively. Due to additive effects, 9 and 9 could make phenotypic values of traits increase and decrease to some extent, 
respectively. Notably, a dominant genetic effect of the QTLs could not be computed in this experiment because the individuals in the RIL population were homologous.

\begin{tabular}{|c|c|c|c|c|c|c|c|c|c|}
\hline Traits & $\mathrm{N}$ regimes & QTL name & Chromosome & Closest marker (bin) & Position (cM) & Interval (cM) & LOD & $\mathrm{R}^{2}$ & Additive effect \\
\hline \multirow[t]{2}{*}{$\mathrm{PH}(\mathrm{cm})$} & HNR & $q P H-h n 1$ & 1 & Umc1035 (1.06) & 93.5 & 5.9 & 7.1 & 17.3 & -9.6 \\
\hline & LNR & $q P H-\ln 1$ & 1 & Umc1035 (1.06) & 92.5 & 6.9 & 6.3 & 15.6 & -9.2 \\
\hline \multirow[t]{8}{*}{$\mathrm{EH}(\mathrm{cm})$} & HNR & $q E H-h n l$ & 1 & Umc1358 (1.07) & 110.4 & 2.1 & 6.1 & 10.0 & -4.3 \\
\hline & & $q E H-h n 9 a$ & 9 & $\mathrm{Nc} 134(9.03)$ & 63.6 & 6.0 & 5.3 & 11.5 & -4.5 \\
\hline & & $q E H-h n 9 b$ & 9 & Bnlg1375 (9.07) & 121.0 & 0.0 & 6.9 & 10.3 & 4.3 \\
\hline & LNR & $q E H-\ln 1 a$ & 1 & Bnlg1178 (1.02) & 22.0 & 22.0 & 3.0 & 17.2 & 5.4 \\
\hline & & $q E H-\ln 1 b$ & 1 & Bnlg1866 (1.03) & 51.0 & 0.0 & 3.1 & 4.7 & 2.9 \\
\hline & & $q E H-\ln 1 c$ & 1 & Umc1358 (1.07) & 109.4 & 3.1 & 5.7 & 9.8 & -4.2 \\
\hline & & $q E H-\ln 9 a$ & 9 & Phi065 (9.03) & 54.4 & 0.0 & 7.2 & 10.6 & -4.2 \\
\hline & & $q E H-\ln 9 b$ & 9 & Bnlg1375 (9.07) & 121.0 & 0.0 & 6.0 & 8.7 & 3.9 \\
\hline \multirow{8}{*}{$\mathrm{LN}$} & HNR & $q L N-h n 2$ & 2 & Bnlg125 (2.03) & 94.7 & 3.0 & 4.2 & 8.3 & -0.4 \\
\hline & & $q L N-h n 7$ & 7 & Umc1295 (7.04) & 33.3 & 18.9 & 3.8 & 14.1 & 0.5 \\
\hline & & $q L N-h n 9 a$ & 9 & Nc134 (9.03) & 63.6 & 6.0 & 6.0 & 14.5 & -0.5 \\
\hline & & $q L N-h n 9 b$ & 9 & Bnlg1129 (9.08) & 135.0 & 8.6 & 6.2 & 18.9 & 0.5 \\
\hline & LNR & $q L N-\ln 3$ & 3 & Bnlg1035 (3.05) & 73.6 & 2.0 & 3.6 & 8.3 & 0.4 \\
\hline & & $q L N-\ln 7$ & 7 & Bnlg1792 (7.02) & 27.3 & 16.0 & 4.5 & 15.3 & 0.5 \\
\hline & & $q L N-\ln 9 a$ & 9 & Phi022 (9.03) & 43.7 & 3.1 & 7.4 & 13.5 & -0.5 \\
\hline & & $q L N-\ln 9 b$ & 9 & Bnlg1375 (9.07) & 129.0 & 8.0 & 7.8 & 20.5 & 0.5 \\
\hline
\end{tabular}

anterval between QTL and its closest marker; $\mathrm{R}^{2}=$ percentage of phenotypic variation explained by QTL. LOD $=109$ 10 of odds ratio; $\mathrm{PH}=$ plant height; $\mathrm{EH}=$ ear height; $\mathrm{LN}=$ leaf number; $\mathrm{HNR}=$ high $\mathrm{N}$ regime; $\mathrm{LNR}=$ low $\mathrm{N}$ regime.

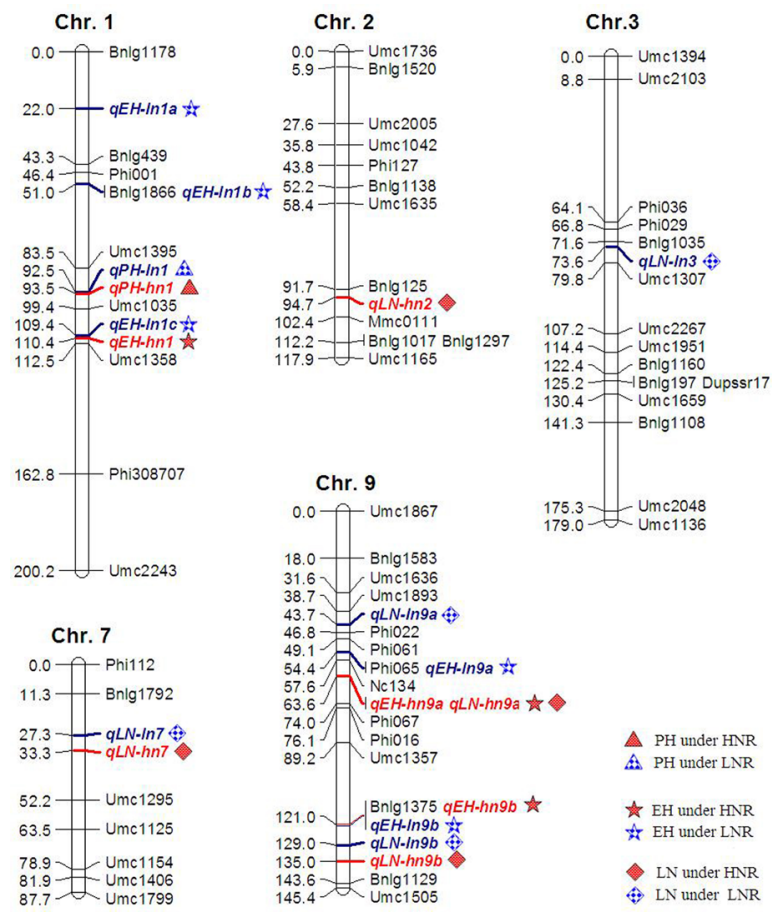

Figure 2. Chromosomal positions of the QTLs for plant height (PH), ear height (EH), and leaf number (LN). The 18 QTLs were indicated with different shapes and colors, red for high N regime (HNR) and blue for low N regime (LNR). 
The 18 QTLs were analyzed and mapped (Table 6 and Figure 2). However, the actual number of QTLs should be less than 18 because some QTLs were identified under both N regimes and can be combined on the basis of their chromosomal positions and respective additive effects. For example, the distance between $q P H-h n 1$ and $q P H-\ln 1$ in the map was only $1.0 \mathrm{cM}$, and the additive effect of each locus was nearly identical; thus, it was concluded that these loci represented the same QTL.

\section{DISCUSSION}

Plant architecture is one of the most important agronomic traits in maize and is related to grain yield and biomass. Plant architecture has long attracted the attention of breeders for achieving the ideal architecture in production of crop plants (Ku et al., 2010). To understand the genetic basis more clearly and develop MAS for plant breeding, 3 key quantitative traits associated with plant architecture, $\mathrm{PH}, \mathrm{EH}$, and LN, were selected for QTL mapping by using an immortal RIL population across $2 \mathrm{~N}$ regimes.

For traits PH and EH, many studies on QTL mapping have been reported, and a large number of QTLs have been identified on 10 chromosomes in maize (Kraja and Dudley, 2000; Sibov et al., 2003; Lima et al., 2006; Malosetti et al., 2008; Bai et al., 2010). No new QTLs were identified for $\mathrm{PH}$ and $\mathrm{EH}$, and our experiments were similar to previous studies in many aspects such as the identity of the parents, population type, genetic map, and ecological conditions. However, previous studies were focused on $\mathrm{F}_{2}$ populations (Malosetti et al., 2008; Zhang et al., 2010). The $\mathrm{F}_{2}$ population can only be used once because the plants cannot propagate. In contrast, the RIL population used in our study is immortal; hence, it could be applied again in different regions and times because of the homogenous population (Bai et al., 2010). In addition, previous environments designed for QTL mapping of PH and EH were mainly based on differences in the water content of the soil (Malosetti et al., 2008; Zhang et al., 2010). Different $\mathrm{N}$ regimes, which are described herein, have rarely been used for QTL detection (Agrama et al., 1999).

Only a few studies have reported QTLs for LN (Jiang et al., 1999; Tang et al., 2007; Wang et al., 2008). Previous results indicated that all 10 chromosomes in maize contain QTLs controlling LN, except for chromosome 5. Compared with previous studies, some QTLs identified in the present study were new loci; for example, one QTL mapped to bin 9.07-9.08 of chromosome 9. Previously analyzed ecological environments included mainly different locations during the same year or different years at the same location. To the best of our knowledge, this is the first study to map QTLs for LN under different $\mathrm{N}$ regimes.

Among the QTLs identified in our experiment, $3 \mathrm{EH}$ loci had $0 \mathrm{cM}$ of mapping distance to linked markers: 1 QTL was identified under both $\mathrm{N}$ regimes $(q E H-h n 9 b$ or $q E H$ $\ln 9 b)$, and 2 QTLs were identified only under LNR $(q E H-\ln 1 b$ and $q E H-\ln 9 a)$. This finding suggested that the linked markers co-segregated with the genes controlling the traits, and they could hence be used for MAS. The other QTLs, with over $0 \mathrm{cM}$ of mapping interval to their closest markers, may be mapped in more detail by using other molecular markers that target specific chromosomal regions. This research is in progress with the established immortal RIL population and genetic map. 


\section{ACKNOWLEDGMENTS}

Research supported by the Scientific Research Fund of the Sichuan Provincial Education Department (\#13ZA0012) of China.

\section{REFERENCES}

Agrama HAS, Zakaria AG, Said FB and Tuinstra M (1999). Identification of quantitative trait loci for nitrogen use efficiency in maize. Mol. Breed. 5: 187-195.

Bai W, Zhang H, Zhang Z, Teng F, et al. (2010). The evidence for non-additive effect as the main genetic component of plant height and ear height in maize using introgression line populations. Plant Breed. 129: 376-384.

Balint-Kurti PJ, Zwonitzer JC, Pe ME, Pea G, et al. (2008). Identification of quantitative trait Loci for resistance to southern leaf blight and days to anthesis in two maize recombinant inbred line populations. Phytopathology 98: 315-320.

Blair MW, Sandoval TA, Caldas GV, Beebe SE, et al. (2010). Quantitative trait locus analysis of seed phosphorus and seed phytate content in a recombinant inbred line population of common bean. Crop Sci. 49: 237-246.

Chen F, Zhu SW, Xiang Y, Jiang HY, et al. (2010). Molecular marker-assisted selection of the ae alleles in maize. Genet. Mol. Res. 9: 1074-1084.

Doerge RW and Churchill GA (1996). Permutation tests for multiple loci affecting a quantitative character. Genetics 142: 285-294.

$\mathrm{Du}$ W, Yu D and Fu S (2009). Detection of quantitative trait loci for yield and drought tolerance traits in soybean using a recombinant inbred line population. J. Integr. Plant Biol. 51: 868-878.

Hao ZF, Li XH, Liu XL, Xie CX, et al. (2011). Meta-analysis of constitutive and adaptive QTL for drought tolerance in maize. Euphytica 174: 165-177.

Ibitoye DO and Akin-Idowu PE (2010). Marker-assisted-selection (MAS): A fast track to increase genetic gain in horticultural crop breeding. Afr. J. Biotechnol. 9: 8889-8895.

Jantaboon J, Siangliw M, Im-mark S, Jamboonsri W, et al. (2011). Ideotype breeding for submergence tolerance and cooking quality by marker-assisted selection in rice. Field Crops Res. 123: 206-213.

Jiang C, Edmeades GO, Armstead I, Lafitte HR, et al. (1999). Genetic analysis of adaptation differences between highland and lowland tropical maize using molecular markers. Theor. Appl. Genet. 99: 1106-1119.

Kebrom TH and Brutnell TP (2007). The molecular analysis of the shade avoidance syndrome in the grasses has begun. J. Exp. Bot. 58: 3079-3089.

Kraja AT and Dudley JW (2000). QTL analysis of two maize inbred line crosses. Maydica 45: 1-12.

Ku LX, Zhao WM, Zhang J, Wu LC, et al. (2010). Quantitative trait loci mapping of leaf angle and leaf orientation value in maize (Zea mays L.). Theor. Appl. Genet. 121: 951-959.

Kumar JR and Kumar BT (2009). Quantitative trait loci (QTL) mapping for crop improvement. Res. J. Biotechnol. 4: $67-79$.

Kumar J, Mir RR, Kumar N and Kumar A (2010). Marker-assisted selection for pre-harvest sprouting tolerance and leaf rust resistance in bread wheat. Plant Breed. 129: 617-621.

Li XB, Yan WG, Agrama H, Jia LM, et al. (2012). Unraveling the complex trait of harvest index with association mapping in rice (Oryza sativa L.). PLoS One 7: e29350.

Liao CJ, Wang YH, Lin JX, Lu HD, et al. (2011). Preliminary analysis on key agronomic traits relating to biomass and quality of silage maize. Fujian J. Agric. Sci. 26: 572-576.

Lima MDA, de Souza CL, Bento DAV, Bento DAV, et al. (2006). Mapping QTL for grain yield and plant traits in a tropical maize population. Mol. Breed. 17: 227-239.

Liu JC, Chu Q, Cai HG, Mi GH, et al. (2010). SSR linkage map construction and QTL mapping for leaf area in maize. $Y i$ Chuan 32: 625-631.

Liu XH, Tan ZB and Tan ZB (2009). Molecular mapping of a major QTL conferring resistance to SCMV based on immortal RIL population in maize. Euphytica 167: 229-235.

Lu M, Zhou F, Xie CX, Li MS, et al. (2007). Construction of a SSR linkage map and mapping of quantitative trait loci (QTL) for leaf angle and leaf orientation with an elite maize hybrid. Yi Chuan 29: 1131-1138.

Lu ZY, Li MS, Xie ZJ, Xie CX, et al. (2010). Study on the trend of yield components among maize hybrids in China. $J$. Maize Sci. 18: 13-17, 22.

Malosetti M, Ribaut JM, Vargas M, Crossa J, et al. (2008). A multi-trait multi-environment QTL mixed model with an 
application to drought and nitrogen stress trials in maize (Zea mays L.). Euphytica 161: 241-257.

Messmer R, Fracheboud Y, Banziger M, Vargas M, et al. (2009). Drought stress and tropical maize: QTL-by-environment interactions and stability of QTLs across environments for yield components and secondary traits. Theor. Appl. Genet. 119: 913-930.

Mickelson SM, Stuber CS, Senior L and Kaeppler SM (2002). Quantitative trait loci controlling leaf and tassel traits in a B73 x M o17 population of maize. Crop Sci. 42: 1902-1909.

Qiu LJ, Guo Y, Li Y, Wang XB, et al. (2011). Novel gene discovery of crops in China: status, challenging, and perspective. Acta Agronom. Sin. 37: 1-17.

Ribaut JM, Fracheboud Y, Monneveux P, Banziger M, et al. (2007). Quantitative trait loci for yield and correlated traits under high and low soil nitrogen conditions in tropical maize. Mol. Breed. 20: 15-29.

Sibov ST, de Souza CLJ, Garcia AA, Silva AR, et al. (2003). Molecular mapping in tropical maize (Zea mays L.) using microsatellite markers. 2. Quantitative trait loci (QTL) for grain yield, plant height, ear height and grain moisture. Hereditas 139: 107-115.

Stendal C, Casler MD and Jung G (2006). Marker-assisted selection for neutral detergent fiber in smooth bromegrass. Crop Sci. 46: 303-311.

Tang JH, Teng WT, Yan JB, Ma XQ, et al. (2007). Genetic dissection of plant height by molecular markers using a population of recombinant inbred lines in maize. Euphytica 155: 117-124.

Tollenaar M and Wu J (1999). Yield improvement in temperate maize is attributable to greater stress tolerance. Crop Sci. 39: 1597-1604.

Tsonev S, Todorovska E, Avramova V, Kolev S, et al. (2009). Genomics assisted improvement of drought tolerance in maize: QTL approaches. Biotechnol. Biotechnol. Equipment 23: 1410-1413.

Voorrips RE (2002). MapChart: software for the graphical presentation of linkage maps and QTLs. J. Hered. 93: 77-78.

Wang CL, Cheng FF, Sun ZH, Tang JH, et al. (2008). Genetic analysis of photoperiod sensitivity in a tropical by temperate maize recombinant inbred population using molecular markers. Theor. Appl. Genet. 117: 1129-1139.

Wang S, Basten CJ and Zeng ZB (2010). Windows QTL Cartographer 2.5. Department of Statistics, North Carolina State University, Raleigh NC. Availabe at [http://statgen.ncsu.edu/qtlcart/WQTLCart.htm]. Accessed March 10, 2010.

Xiao YN, Li XH, George ML, Li MS, et al. (2005). Quantitative trait locus analysis of drought tolerance and yield in maize in China. Plant Mol. Biol. Rep. 23: 155-165.

Zhang Y, Li YX, Wang Y, Liu ZZ, et al. (2010). Stability of QTL across environments and QTL-by-environment interactions for plant and ear height in maize. Agric. Sci. China 9: 1400-1412.

Zhou GS, Liu F, Cao JH, Yue B, et al. (2011). Detecting quantitative trait loci for water use efficiency in rice using a recombinant inbred line population. Chin. Sci. Bull. 56: 1481-1487. 